\title{
The Effects of Asymmetric Dimethylarginine (ADMA), Nitric Oxide (NO) and Homocysteine (Hcy) on Progression of Mild Chronic Kidney Disease (CKD): Relationship Between Clinical and Biochemical Parameters
}

\author{
A. Atamer ${ }^{1}$, S. Alisir Ecder ${ }^{2}$, Y. Atamer ${ }^{3}$, \\ Y. Kocyigit ${ }^{4}$, N. Bozkurt Yigit ${ }^{5}$ and T. Ecder 6 \\ ${ }^{1}$ Haydarpasa Training and Research Hospital, \\ Department of Internal Medicine, Division of Gastroenterology, Istanbul \\ ${ }^{2}$ Goztepe Training and Research Hospital, \\ Department of Internal Medicine, Division of Nephrology, Istanbul \\ ${ }^{3}$ Dicle University Medical Faculty, Department of Clinical Biochemistry, Diyarbakir \\ ${ }^{4}$ Dicle University Medical Faculty, Department of Physiology, Diyarbakir \\ ${ }^{5}$ Yalova University, Termal Vocational School, \\ Department of Physical Medicine and Rehabilitation, Yalova \\ ${ }^{6}$ Istanbul University, Istanbul Medical Faculty, \\ Department of Internal Medicine, Division of Nephrology, Istanbul, \\ Turkey
}

\section{Introduction}

Chronic kidney disease (CKD) is a syndrome characterized by the progressive and irrevocable loss of nephrons due to several diseases. Chronic kidney disease has a varying spectrum ranging from normal renal function to uremic syndrome. Actually, the stages of renal failure have interpenetrated each other and it is not possible to draw a clear line between them. The most important reason of mortality and morbidity of patients with CKD are cardiovascular diseases and atherosclerotic complications; cardiac insufficiency 15\%, myocardial infarction $10 \%$, pericarditis $3 \%(1,2)$. Development of vascular injury in CKD is caused by both classic (Framingham) risk factors (hypertension, dyslipidemia, smoking, diabetes mellitus) and CKD specific factors (anaemia, secondary hyperparathyroidism etc). Besides, there are papers reporting that recently defined potential risk factors such as homocysteine (Hcy), C-reactive protein (CRP), interleukin-6 (IL-6), fibrinogen, soluble intracellular adhesion molecule (sICAM-1), asymmetric dimethyl arginine (ADMA), cardiac specific troponin-I (cTnI), advanced glycation endproducts have a role in the development of accelerated atherosclerosis seen in patients with CKD (2-13). Asymmetric dimethylarginine (ADMA) is an endogenous competitive inhibitor of nitric oxide (NO) synthase and it is a guanidine analogue of L-arginine aminoacid detectable in human urine 
and plasma synthesized from endothelial cells (Figure 1). It is shown that high ADMA level increase the cardiovascular incident risk by $34 \%$ and mortality risk by $52 \%$ (4-8). Increased ADMA concentration has a high prevalence in hyperhomocysteinemia, coronary artery diseases, hypercholesterolemia, diabetes mellitus, hypertension, preeclampsia, peripheral arterial occlusive disease, impaired renal function and other diseases $(7,9,10)$. Reduced nitric oxide (NO)-dependent vasodilation is regarded as an early indicator of atherosclerotic diseases $(7,14)$. It is documented that adult patients with renal failure have 2-6 times higher ADMA than healthy subjects due to reduced renal excretion and reduced enzymatic degradation (15). NO is synthesized from L-arginine via NO synthase enzyme. NO inhibition decreases endothelial derived vasodilation and increases vascular resistance. Reduced NO availability can occur in patients with CKD. Moreover CKD can contribute to the accelaration of hypertension and cardiovascular complications. It appears that the increase in endogenic NO inhibitors like ADMA plays a major role in this process $(11,15-$ 17). It has been shown that Hcy stimulates ADMA formation and plasma ADMA levels elevate in humans and animals by hyperhomocysteinemia (18-20). Increased serum Hcy level in adult CKD patients is an independent risk factor for cardiovascular system mortality. Elevated ADMA and hyperhomocysteinemia may be due to decreased renal excretion (18-22). It is reported that ADMA formation may be related with Hcy metabolism $(18,19)$. It was found that there is a significant interaction of serum fibrinogen and CKD with respect to risk of both fatal/nonfatal coronary events and death (20-24).

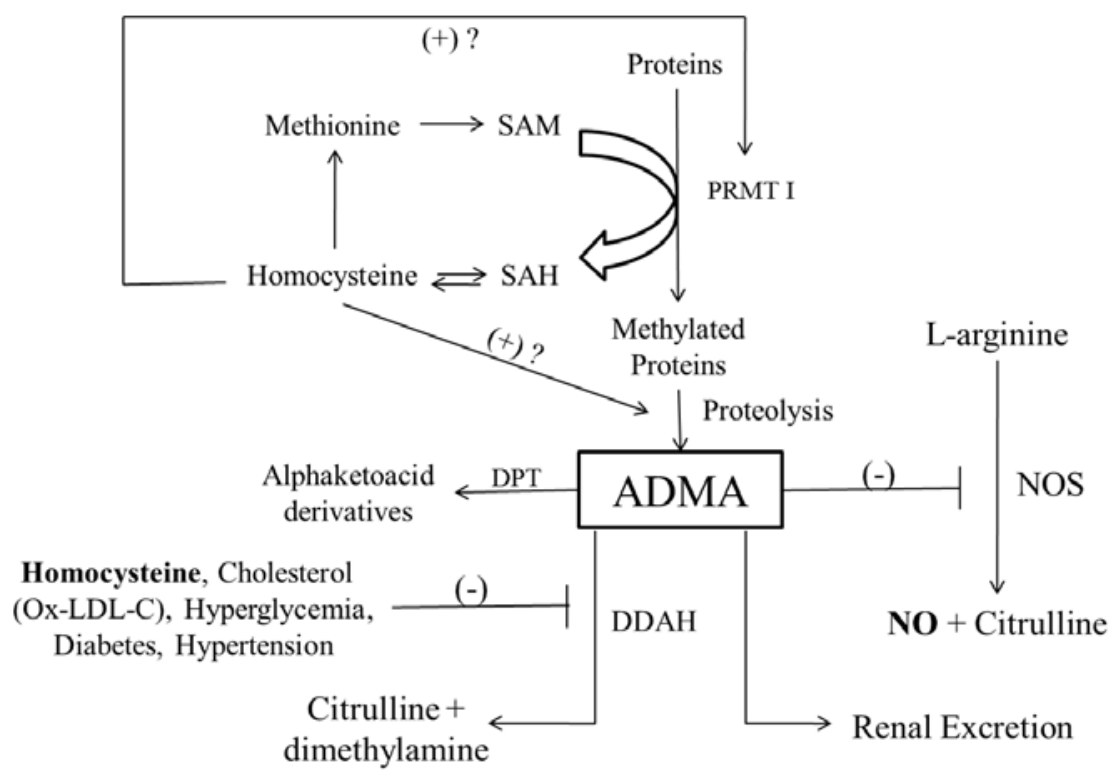

PRMT I: Protein arginine methyltransferase type I; DDAH: Dimethylaminohydrolase; DPT: Dimethyl arginine piruvate aminotransferase; NOS: Nitric oxide synthase; SAM: S-Adenosylmethionine; SAH: S-Adenosylhomocysteine; Ox LDL-C: Oxidized low density lipoprotein cholesterol

Fig. 1. Biochemical pathway for generation and degradation of ADMA and homocysteine. 
The aim of this study was to investigate the role of uremia-related cardiovascular risk factors, such as ADMA, NO, Hcy and fibrinogen, in the pathogenesis and progression of early stage CKD and to evaluate the relation of these parameters with each other.

\section{Material and methods}

\subsection{Subjects}

This prospective study was carried out in 65 untreated mild chronic kidney disease (35 men and 30 women; mean age $55.2 \pm 9.6$ years) and 65 healthy control subjects with matched age, sex and body mass index (BMI). The creatinine clearance was calculated by the Cockcroft-Gault Formula (25). Patients having creatinine clearance less than $75 \mathrm{ml} / \mathrm{min}$ were considered to have mild CKD. Body mass index was determined as weight divided by the square of height $\left(\mathrm{kg} / \mathrm{m}^{2}\right)$. The underlying causes of CKD were glomerulonephritis $(n=17)$, interstitial nephropathy $(n=12)$, autosomal dominant polycystic kidney disease $(n=13)$, chronic pyelonephritis $(n=7)$ and urological problems $(n=5)$. No cause was identified in 11 cases. The exclusion criteria were diabetes mellitus, active hepatitis, malignancy, smoking and infectious disease. Patients using vitamin supplements were also excluded.

The study protocol was approved by the Ethics Committee of the Dicle University School of Medicine (Diyarbakir, Turkey) and written informed consent was obtained from each participant.

\subsection{Methods}

In all patients, venous blood samples were drawn between 7:00 AM after a 12-h fastened, and the serum was frozen at $-70^{\circ} \mathrm{C}$ in aliquots until biochemical analysis were performed.

ADMA Measurement: ADMA was measured by HPLC according to the method described by Chen et al. (26). Mobile phases consisting of $50 \mathrm{mM}$ sodium acetate ( $\mathrm{pH}$ 6.8), methanol and tetrahydrofuran (THF) (A, 82:17:1; B, 22:77:1) were used. All separations were performed at $27^{\circ} \mathrm{C}$ and at a flow-rate of $1.0 \mathrm{ml} / \mathrm{min}$. The wavelengths of fluorescence detector were set at $338 \mathrm{~nm}$ and $425 \mathrm{~nm}$ for excitation and emission, respectively. $20 \mathrm{mg}$ of 5-sulfosalicylic acid (5-SSA) was added to $1 \mathrm{ml}$ plasma, and the mixture was left in an ice bath for $10 \mathrm{~min}$. The precipitated protein was removed by centrifugation at $2000 \mathrm{~g}$ for $10 \mathrm{~min}$. oPhthaldialdehyde (OPA) $(10 \mathrm{mg})$ was dissolved in $0.5 \mathrm{ml}$ of methanol, and $2 \mathrm{ml}$ of $0.4 \mathrm{M}$ borate buffer ( $0.4 \mathrm{M}$ boric acid adjusted to $\mathrm{pH} 10.0$ with potassium hydroxide) and $30 \mu \mathrm{l}$ of mercaptoethanol were added. The derivatization was performed by mixing $10 \mu l$ of sample or working standard solution and $100 \mu \mathrm{l}$ of OPA reagent and reacting for $3 \mathrm{~min}$ before autoinjecting onto the column.

NO Measurement: The serum level of NO was measured using a colorimetric method based on the Griess reaction (27), in which nitrite is reacted with sulphanilamide and $\mathrm{N}-(1-$ naphthyl) ethylenediamine to produce an azo dye that can be detected at $540 \mathrm{~nm}$. This was carried out after enzymatic reduction of nitrate to nitrite with nitrate reductase.

Hcy Measurement: Serum level of Hcy was measured using HPLC with fluorescence detection (Shimadzu RF-10A fluorescence detector; Shimadzu Co., Kyoto, Japan). 
Urea, creatinine, calcium, phosphate, albumin, protein, high sensitive CRP (hsCRP), insulin, glucose, total cholesterol, high-density lipoprotein cholesterol (HDL-C), low-density lipoprotein cholesterol (LDL-C) and triglyceride assays were determined by standard laboratory methods according to the established methodology. The serum level of fibrinogen was measured by the Clauss method using a commercial kit. All routine laboratory measurements were carried out using certified assay methods.

Statistical analysis of the differences between groups of subjects was performed using the Kolmogorov-Smirnov and unpaired student's t-test or by the Mann-Whitney nonparametric test as appropriate. Pearson's correlation analyses were performed.

\section{Results}

Serum levels of ADMA, Hcy, creatinine, LDL-C and hsCRP were significantly $(p<0.001)$ higher in patients with mild CKD than in healthy controls. Also, systolic and diastolic blood pressures were increased $(p<0.001)$. There were no significant differences in levels of serum fasting blood glucose, insulin, total cholesterol, HDL-C, triglyceride, calcium and phosphate between the mild CKD and healthy controls $(\mathrm{P}>0.05)$. Serum $\mathrm{NO}$ and creatinine clearance levels were decreased in patients with mild CKD than in healthy controls $(p<0.001)$. Clinical and laboratory data are reported in Table 1. In multiple linear regression analysis, ADMA level was negatively correlated with NO $(\mathrm{r}=-0.861 ; \mathrm{p}<0.001)$ as shown in Figure $2 \mathrm{~A}$, and positively correlated with Hcy $(\mathrm{r}=0.547 ; \mathrm{p}<0.001$, Figure $2 \mathrm{~B})$ and fibrinogen $(\mathrm{r}=0.704$; $\mathrm{p}<0.01$, Figure 2C). ADMA level was positively correlated with creatinine $(r=0.510 ; p<0.001)$, LDL-C $(\mathrm{r}=0.420 ; \mathrm{p}<0.01)$, hsCRP $(\mathrm{r}=0.525 ; \mathrm{p}<0.001)$, systolic $(\mathrm{r}=0.375 ; \mathrm{p}<0.001)$ and diastolic blood pressure $(\mathrm{r}=0.410 ; \mathrm{p}<0.001)$ levels. ADMA level was negatively correlated with GFR $(\mathrm{r}=-0.720 ; \mathrm{p}<0.001)$. Also, serum NO level was negatively correlated with homocystein $(\mathrm{r}=-$ 0.390; $\mathrm{p}<0.001$, Figure 3). We found no association between ADMA and HDL-C or other parameters in either subjects with mild CKD.

\section{Discussion}

The findings of the present study are as follows: (1) Serum ADMA level is increased in patients with CKD compared with healthy subjects and is associated with decreased NO and GFR. (2) Elevation of circulating serum ADMA is associated with increased Hcy and fibrinogen in CKD patients. (3) Serum NO level as dependent variable was also negatively correlated with Hcy. Our findings suggested that the ADMA levels can reflect a possible independent role in CKD pathogenesis. Increased ADMA serum levels cause persistent renal vasoconstriction and sodium retention, and contributes to the development of high blood pressure (11). In addition, it might influence NO and GFR levels and affect atherosclerosis formation.

Several studies suggested that ADMA level can be an independent risk factor for progression of CKD (3-13). Elevated ADMA reduces bioavailability of NO and induces endothelial dysfunction and may be involved in the pathophysiology of cardiovascular disease in CKD (8). ADMA fulfils many of the characteristic features of an uremic toxin $(14,15)$. Elevation of circulated ADMA, an endogenous inhibitor of nitric oxide synthase, is an independent risk factor for cardiovascular diseases in predialysis patients with CKD $(5,14,15)$. High ADMA levels lead to NO depletion, impaired endothelium-dependent 
The Effects of Asymmetric Dimethylarginine (ADMA), Nitric Oxide (NO) and Homocysteine (Hcy) on Progression of Mild Chronic Kidney Disease (CKD): Relationship Between Clinical and...

\begin{tabular}{|c|c|c|}
\hline & $\begin{array}{l}\text { Healthy Subjects } \\
\qquad(n=65)\end{array}$ & $\begin{array}{l}\text { Chronic Kidney Disease } \\
\qquad(\mathrm{n}=65)\end{array}$ \\
\hline Age (years) & $54.9 \pm 10.1$ & $55.2 \pm 9.6$ \\
\hline Number of patients $(\mathrm{M} / \mathrm{F})$ & $35 / 30$ & $35 / 30$ \\
\hline Body mass index (kg/m2) & $24.90 \pm 2.1$ & $24.70 \pm 2.6$ \\
\hline Systolic BP (mmHg) & $110.20 \pm 10.4$ & *128.40 \pm 22.4 \\
\hline Diastolic BP (mmHg) & $72.20 \pm 11.6$ & *84.40 \pm 16.3 \\
\hline Creatinine clearance (ml/min) & $90.20 \pm 15.1$ & $* 52.50 \pm 15.3$ \\
\hline Urea $(\mathrm{mg} / \mathrm{dl})$ & $31.50 \pm 6.2$ & *61.30 \pm 14.6 \\
\hline Creatinine $(\mathrm{mg} / \mathrm{dl})$ & $1.20 \pm 0.42$ & *1.61 \pm 0.73 \\
\hline Calcium (mg/dl) & $8.73 \pm 1.2$ & $8.91 \pm 1.08$ \\
\hline Phosphate (mg/dl) & $4.10 \pm 1.09$ & $4.09 \pm 1.2$ \\
\hline Albumin (g/dl) & $3.82 \pm 0.9$ & $3.94 \pm 0.5$ \\
\hline Protein $(\mathrm{g} / \mathrm{dl})$ & $6.40 \pm 1.1$ & $6.01 \pm 0.3$ \\
\hline Glucose (mg/dl) & $87.90 \pm 16.2$ & $90.10 \pm 15.4$ \\
\hline Insulin $(\mu \mathrm{u} / \mathrm{ml})$ & $11.60 \pm 2.9$ & $12.04 \pm 2.83$ \\
\hline Triglyceride(mg/dl) & $118.30 \pm 20.2$ & $120.10 \pm 18.5$ \\
\hline Total cholesterol (mg/dl) & $184.20 \pm 22.1$ & $185.60 \pm 19.4$ \\
\hline HDL-C (mg/dl) & $45.80 \pm 12.4$ & $42.02 \pm 14.3$ \\
\hline LDL-C (mg/dl) & $113.20 \pm 12.8$ & *142.12 \pm 18.6 \\
\hline hsCRP (mg/dl) & $1.914 \pm 0.667$ & *7.048 \pm 2.249 \\
\hline Fibrinogen $(\mathrm{g} / \mathrm{L})$ & $2.835 \pm 0.646$ & *4.574 \pm 0.521 \\
\hline $\operatorname{ADMA}(\mu \mathrm{mol} / \mathrm{L})$ & $0.512 \pm 0.116$ & $* 0.837 \pm 0.189$ \\
\hline Nitric oxide $(\mu \mathrm{mol} / \mathrm{L})$ & $75.67 \pm 8.626$ & *44.31 \pm 7.811 \\
\hline Homocystein $(\mu \mathrm{mol} / \mathrm{L})$ & $6.256 \pm 1.629$ & ${ }^{*} 18.37 \pm 3.192$ \\
\hline
\end{tabular}

${ }^{*} \mathrm{P}<0.001$; Data are reported as means $\pm \mathrm{SD}$.

BP: Blood Pressure; HDL-C: High Density Lipoprotein Cholesterol; LDL-C: Low Density Lipoprotein Cholesterol; hsCRP: High sensitive C Reactive Protein; ADMA: Asymmetric dimethylarginine

Table 1. Clinical and laboratory data of patients with CKD and healthy subjects. 


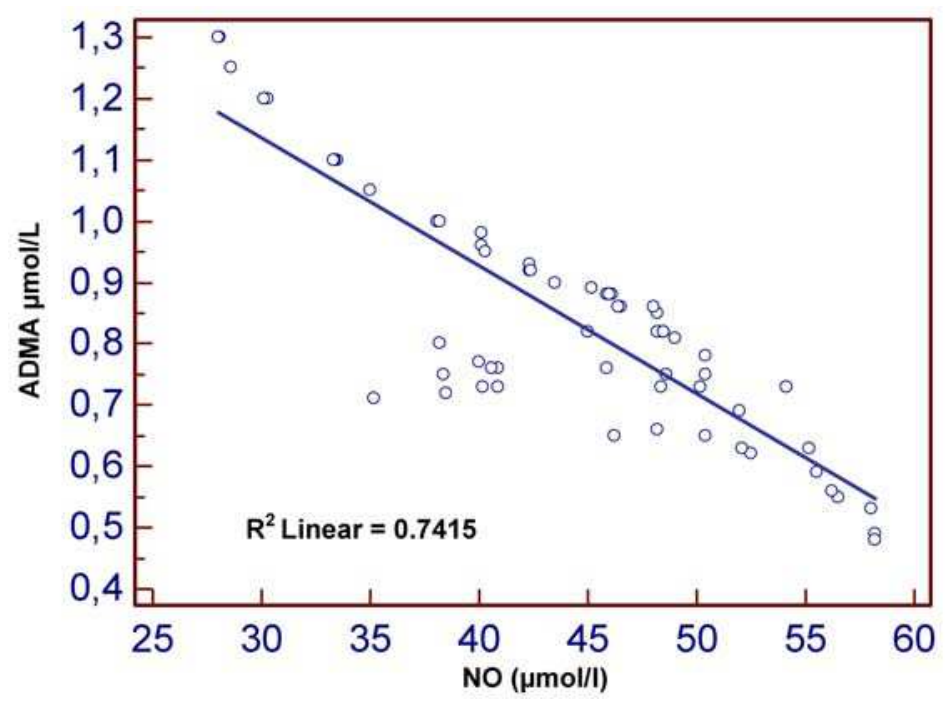

(a)

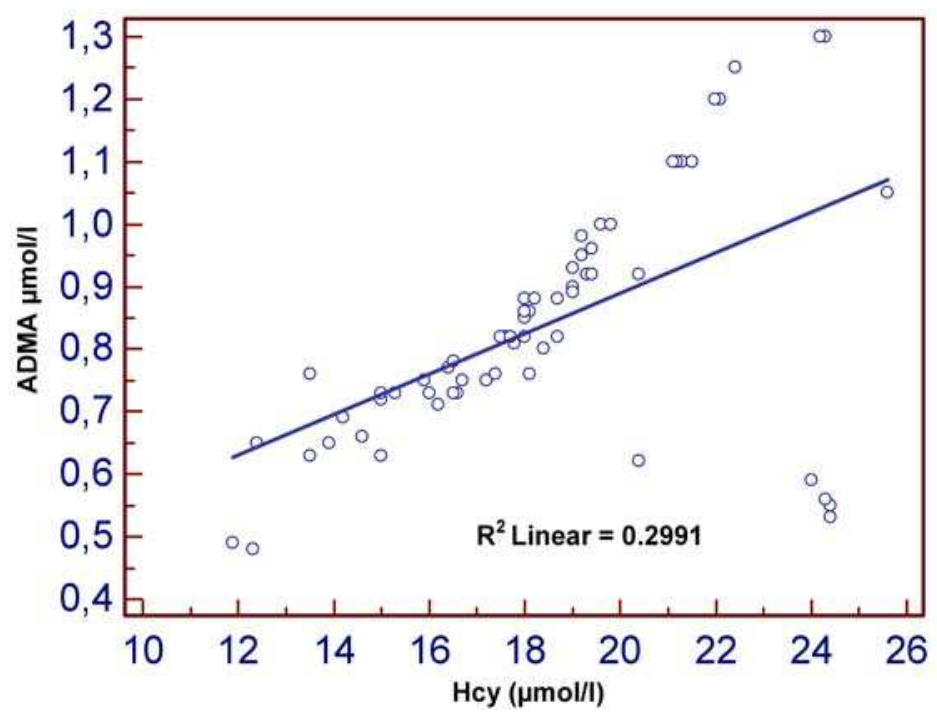

(b) 


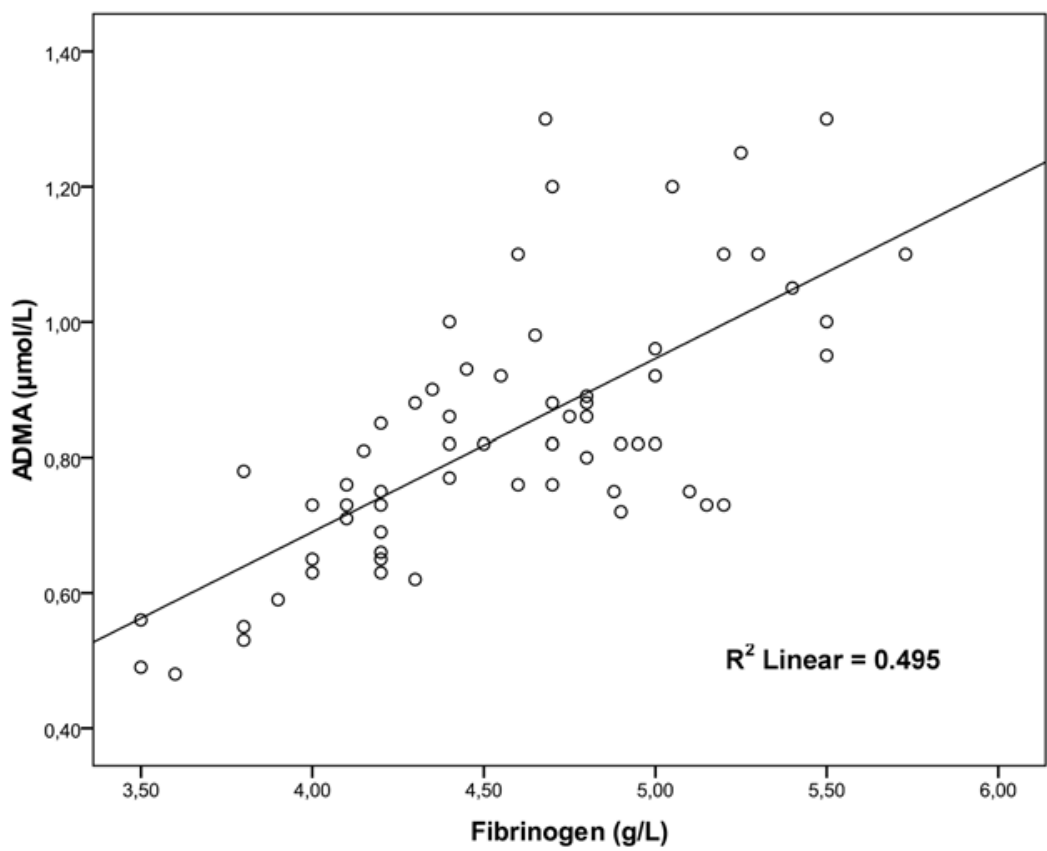

(c)

Fig. 2. Correlation between asymmetric dimethylarginine (ADMA) and (A) nitric oxide (NO), (B) homocysteine (Hcy), and (C) fibrinogen.

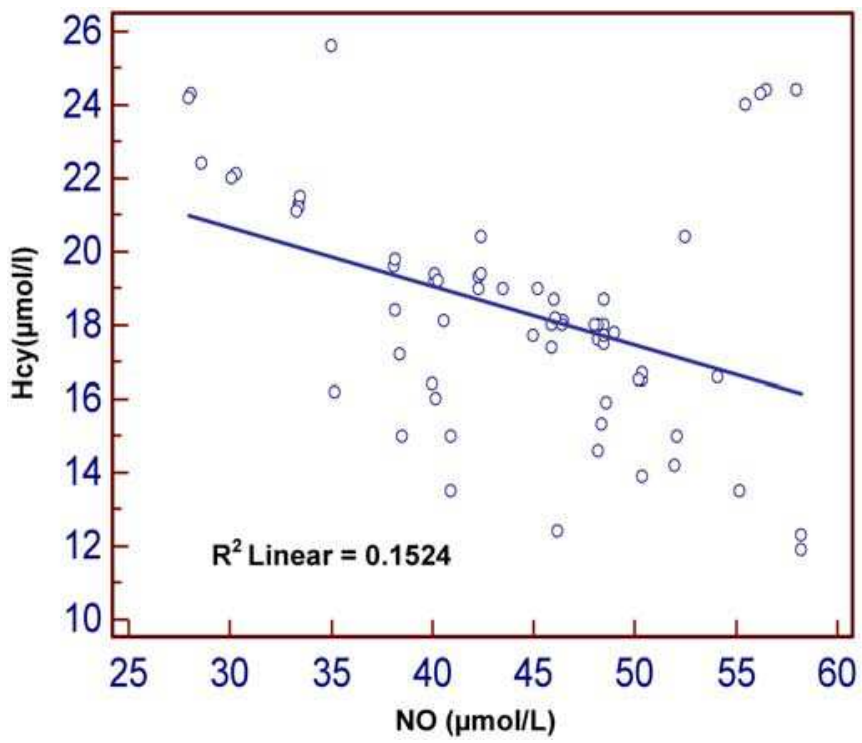

Fig. 3. Correlation between nitric oxide (NO) and homocysteine (Hcy). 
vasodilation and plaque rupture with thrombus formation (8). In addition, increased ADMA level in circulation is a combined result of decreased elimination and reduced activity of ADMA catabolism by dimethylarginine dimethylaminohydrolase (DDAH) $(8,9)$. Elevated plasma levels of ADMA in patients with end stage renal disease (ESRD) were first reported by Vallance et al. (15). Several recent studies have already indicated that elevated plasma ADMA levels could cause cardiovascular morbidity and mortality in progressive chronic kidney disease (4-13). Mihout et al. (9) demonstrated that high plasma ADMA levels contribute to the development of hypertension, oxidative stress, and interstitial and glomerular fibrosis, and peritubular capillary rarefaction. This may be involved in the decline of renal function. Serum levels of ADMA in CKD are predictive of renal survival and of cardiovascular damage. High ADMA levels are associated with endothelial dysfunction and oxidative stres (12). In the study by Young et al. (8), there was a strong association of ADMA with prevalent cardiovascular disease and a modest association with all-cause and cardiovascular disease mortality. ADMA is strongly associated with intimamedia thickness of the carotid artery and left ventricular mass, particularly concentric left ventricular hypertrophy (11).

Coen et al. (12) suggested that ADMA levels could be influenced by the severity of hyperparathyroidsm and contribute to cardivascular death linked to parathyroid hormone (PTH) of hemodialysis patients. Another study conducted by Shi et al (5) has shown that the circulating level of ADMA is an important risk factor of LVH and predicts CVD in predialysis CKD patients.

Selcoki et al. (10) reported that ADMA level was to be one of the strongest risk markers for atherosclerosis in patients with mild and moderate CKD. Ninety percent of ADMA has been metabolized by DDAH, while the other small portion, $10 \%$, is excreted by urinary system. Potential mechanisms of elevated plasma ADMA levels in renal failure are increased protein methylation, increased proteolysis, impaired renal excretion and impaired metabolism by DDAH (18). These results are consistent with data from our study. Our results suggest that high ADMA level can be a significant risk factor for progression of renal dysfunction in the earlier stages of CKD.

Several recent studies found markedly elevated plasma ADMA levels not only in patients with ESRD, but also in patients with progressive CKD (2). It is of note that our results are in line with a recent study by Nakamura et al. (28), who found that elevation of serum ADMA levels play a role in the progression of atherosclerosis and CKD in high-risk patients.

Studies in both the general population and the dialysis population showed a strong and independent link between ADMA, all-cause mortality, and cardiovascular events $(11,12,21,24)$. As a consequence, elevated serum levels of ADMA may be of relevance not only in vascular pathology but also in the pathophysiology of hypertension, and in paralel, in the development of renal damage (13).

When ADMA accumulates in CKD due to defective inactivation and excretion, it is a factor of impaired NO synthesis. The decrease in the generation of NO lead to endothelial malfunction and damage (12). Nitric oxide is an important molecule which has many physiological functions, such as mediating vasodilation, inhibiting atherosclerosis, and modulating the growth of the myocardium (5). Nitric oxide is produced from its precursor L-arginine via a reaction catalyzed by endothelial NO synthase (NOS) $(8,9)$. Endothelium- 
derived nitric oxide is a potent endothelial vasodilator which balances constrictors to regulate blood pressure and vascular tone (9). Leone et al. (35) suggested that NO may play a role in blood pressure regulation. $\mathrm{NO}$ is a cardiovascular protective substance because it causes vasodilation and leucocyte aggregation (10). Nitric oxide also plays a role in regulating renal sodium excretion and renin release (30). Nitric oxide, synthesised from Larginine, contributes to the regulation of blood pressure and to host defence (29). As an endogenous vasodilator it contributes to renal arteriolar tone and modulates relaxation of the mesangium, thus contributing to regulation of glomerular microcirculation. It has antiplatelet and antithrombogenic effects and thus helps prevent thrombosis within the glomerular capillaries (30).

Clinical and experimental evidence suggest that the elevation of ADMA may cause a low production of NO $(11,14-17,29,30)$. Synthesis of NO can be blocked by inhibition of nitric oxide synthase (NOS) activities with guanidino-substituted analogues of L-arginine such as ADMA (28). Accumulation of endogenous ADMA, leading to impaired NO synthesis, might contribute to the hypertension and immune dysfunction associated with chronic renal failure (29). Reduced bioavailability of NO, increased systemic blood pressure, endothelial cell injury and dysfunction are thought to play an important role in progressive kidney damage (7). Endothelial dysfunction due to reduced availability of NO is an early step in the course of atherosclerotic vascular disease (7). Increased ADMA blood levels may contribute to this process. In addition, NO inhibits key processes of atherosclerosis, such as monocyte endothelial adhesion, platelet aggregation, and vascular smooth muscle cell poliferation (31).

In our study, while serum ADMA and Hcy levels were significantly higher in the patients with CKD than in healthy subject, the NO level was significantly lower. Our findings were in agreement with previous studies $(7,9,10,18)$. Low NO is a major feature of chronic kidney diseases. We examined the relationship of ADMA with NO and with Hcy in CKD patients. In this prospective study, high ADMA level was associated with both decreased NO and increased Hcy. Similarly, Strong relationships between increased serum Hcy, fibrinogen, ADMA and decreased NO, GFR and mortality from cardiovascular events have recently been demonstrated. Several prospective clinical studies have shown that ADMA, fibrinogen, Hcy, LDL-C and other cardiovascular risk parameters are effected in patients with CKD, atherosclerosis, hypertension, diabetes and other clinical entities (14$18,22)$.

The major factor for high plasma ADMA levels in renal failure seems to be a decrease DDAH activity, which in turn may be due to increased oxidative stress and/or hyperhomocysteinemia (18). Recent studies show contradictory data regarding the role of hyperhomocysteinemia on cardiovascular morbidity and mortality in CKD patients (32). Rasmussen et al. (22) suggested that elevated homocysteine level is an independent predictor of cardiovascular events in patients with ESRD. Ninomiya et al. (33) suggested that baseline Hcy level showed a significantly inverse association with rate of change in kidney function during the 5 years after being adjusted for confounding factors, including baseline kidney function.

One study indicates a linkage between hyperhomocysteinemia, oxidative stress and ADMA metabolism (32). Recently, it was hypothesized that some of the deleterious effects of 
hyperhomocysteinemia may involve ADMA-related cardiovascular effect in CKD (18-20). Hyperhomocysteinemia, elevated plasma ADMA concentrations have first been described in patients with renal failure (18). Plasma levels of homocysteine and ADMA are elevated in patients with renal failure and both have been associated with cardiovascular events, possibly due to their negative effects on endothelial function. ADMA in methylation of homocystein plays an important role. Elevated homocysteine level is strongly related to renal function and probably due to decreased metabolic clearance (18-20). Homocysteine and ADMA are aminoacids which are biochemically linked by a common synthetic pathway. Homocysteine inhibits DDAH, the enzyme responsible for the breakdown of ADMA. Homocysteine may enhance protein degradation by destabilizing protein structure or by increasing oxidative stress, resulting in ADMA release (18).

Contraversely, Simic-Ogrizovic et al. (24) suggested that although total serum Hcy level was not found to be a predictor of overall and cardiovascular mortality, the role of hyperhomocysteinemia as risk factor for cardiovascular disease cannot be excluded in hemodialysis patients.

We found a strong association between ADMA levels and hyperfibrinogenemia, and hyperhomocysteinemia in our study. In addition, as inflammation index, CRP and fibrinogen were increased. Our results show that increased ADMA, Hcy, hsCRP and fibrinogen levels contribute to the progression of renal disease. Serum levels of ADMA and Hcy may interact and modulate the effect of each other, thus contributing to a common mechanism leading to cardiovascular diseases in CKD. These findings are similar to observations from previous studies (18-21).

The level of serum fibrinogen (an inflammation marker) is increased in CKD. Increased serum fibrinogen level independently predicts cardiac events (20). Shishehbor et al. (19) suggested that Hcy and fibrinogen levels can explain nearly $40 \%$ of the attributable mortality risk from CKD. Bostom et al. (21) suggested that Hcy, lipoprotein(a) (Lp(a)), and fibrinogen interact to promote atherothrombosis, combined hyperhomocysteinemia, hyperfibrinogenemia, and, $\mathrm{Lp}(\mathrm{a})$ excess may contribute to the high incidence of vascular disease sequelae experienced by dialysis patients, which is inadequately explained by traditional cardiovascular disease risk factors. In our present study, the serum level of LDL$\mathrm{C}$ was significantly higher in the patients with CKD than in the healthy subjects. In addition, the ADMA level was positively correlated with LDL-C. The association of increased LDL-C with increased risk of coronary heart disease may be thought as a covariable in the oxidative activation of ADMA synthesis.

Descamps-Latscha et al. (23) thought that CRP, fibrinogen and advanced oxidation protein products (AOPP) levels independently predict atherosclerotic cardiovascular events in patients with CKD in the predialysis phase and might directly contribute to the uremiaassociated accelerated atherogenesis. These findings lend support to the hypothesis that accumulation of ADMA is an important risk factor for cardiovascular events in CKD (2).

Our findings suggest that high ADMA, fibrinogen and Hcy levels and NO deficiency may contribute to the process of atherosclerotic cardiovascular disease and other consequeces of uremia in predialysis patients with CKD. In addition, the ADMA level was associated with hyperhomocysteineamia and hyperfibrinogenemia. 


\section{References}

[1] Zawada ET. Indications for dialysis. Handbook of Dialysis. Daugirdas JT, Ing TS (eds).Little, Brown and Company, Boston 1994: 604-622.

[2] Zoccali C, Mallamaci F, Tripepi G. Traditional and emerging risk factors in end-stage renal disease. Kidney Int 2003;63(suppl85):S105-S110.

[3] Busch M, Franke S, Miller A, et al. Potential risk factors in chronic kidney disease: EGEs, total homocysteine and metabolites, and the C-reactive protein. Kidney Int 2004;66:338-347.

[4] Fujimi-Hayashida A, Ueda S, Yamagishi S, et al. Association of asymmetric dimethylarginine with severity of kidney injury and decline in kidney function in IgA Nephropathy. Am J Nephrol 2011; 33: 1-6.

[5] Shi B, Ni Z, Zhou W, et al. Circulating levels of asymmetric dimethylarginine are an independent risk factor for left ventricular hypertrophy and predict cardiovascular events in pre-dialysis patients with chronic kidney disease. Eur J Intern Med 2010;21(5):444-8.

[6] Abedini S, Meinitzer A, Holme I, et al. Asymmetrical dimethylarginine is associated with renal and cardiovascular outcomes and all-cause mortality in renal transplant recipients. Kidney Int 2010;77(1): 44-50.

[7] Fliser D, Kielsteın JT, Haller H, and Bode-Böger SM. Asymmetric dimethylarginine: A cardiovascular risk factor in renal disease? Kidney Int (Supp) 2003;(84):37-40.

[8] Young JM, Terin N, Wang X, et al. Asymmetric dimethylarginine and mortality in stages 3 to 4 chronic kidney disease. Clin J Am Soc Nephrol 2009;4(6):1115-1120.

[9] Mihout F, Shweke N, Big'e N, et al. Asymmetric dimethylarginine (ADMA) induces chronic kidney disease through a mechanism involving collagen and TGF- $\beta 1$ synthesis. J Pathol 2011; 223(1) : 37-45.

[10] Selcoki Y, Aydın M, İkizek M, Armutcu F, Eryonucu B, Kanbay M. Association between asymmetric dimethylarginine and the severity of coronary artery disease in patients with chronic kidney disease. Turk Neph Dial Transpl 2011;20(1):58-64.

[11] Kielstein JT, Simmel S, Bode-Böger SM, et al. Subpressor dose asymmetric dimethylarginine modulates renal function in humans through nitric oxide synthase inhibition. Kidney Blood Pres Res 2004;27(3):143-147.

[12] Coen G, Mantella D, Sardella D, et al. Asymmetric dimethylarginine, vascular calcifications and parathyroid hormone serum levels in hemodialysis patients. J Nephrol 2009;22(5):616-622.

[13] Kielstein JT, Böger RH, Bode-Böger SM, et al. Low dialysance of asymmetric dimethylarginine (ADMA)- in vivo and in vitro evidence of significant protein binding. Clin Nephrol 2004;62(4):295-300.

[14] Vallance P, Leiper J. Blocking NO synthesis: How, where and why? Nature Reviews Drug Discovery 2002;1(12):939-950

[15] Vallance P, Leone A, Calver A, Collier J, Moncada S. Accumulation of an endogenous inhibitor of nitric oxide synthesis in chronic renal failure. Lancet 1992;339(8793):572-575.

[16] Schmidt RJ, Baylis C. Total nitric oxide production is low in patients with chronic renal disease. Kidney Int 2000;58:1261-1266.

[17] Baylis C. Nitric oxide deficiency in chronic kidney disease. Am J Physiol Renal physiol 2008;294(1):F1-F9. 
[18] van Guldener C, Nanayakkara PW, Stehouwer CD. Homocysteine and asymmetric dimethylarginine (ADMA): biochemically linked but differently related to vascular disease in chronic kidney disease.Clin Chem Lab Med. 2007;45(12):1683-7.

[19] Shishehbor MH, Oliveira LP, Lauer MS, et al. Emerging cardiovascular risk factors that account for a significant portion of attributable mortality risk in chronic kidney disease. Am J Cardiol. 2008 Jun 15;101(12):1741-6. Epub 2008 Apr 9.

[20] Weiner DE, Tighiouart H, Elsayed EF, et al. The relationship between nontraditional risk factors and outcomes in individuals with stage 3 to 4 CKD.Am J Kidney Dis. $2008 \mathrm{Feb} ; 51(2): 212-23$.

[21] Bostom AG, Shemin D, Lapane KL, et al. Hyperhomocysteinemia, hyperfibrinogenemia, and lipoprotein (a) excess in maintenance dialysis patients: a matched case-control study. Atherosclerosis. 1996 Aug 23;125(1):91-101

[22] Rasmussen LE, Svensson M, Jørgensen KA, et al. The content of docosahexaenoic acid in serum phospholipid is inversely correlated with plasma homocysteine levels in patients with end-stage renal disease. Nutr Res. 2010 Aug;30(8):535-40.

[23] Descamps-Latscha B, Witko-Sarsat V, Nguyen-Khoa T,et al. Advanced oxidation protein products as risk factors for atherosclerotic cardiovascular events in nondiabetic predialysis patients. Am J Kidney Dis. 2005 Jan;45(1):39-47

[24] Simic-Ogrizovic S, Stosovic M, Novakovic I, et al. Fuzzy role of hyperhomocysteinemia in hemodialysis patients' mortality. Biomed Pharmacother. 2006 May;60(4):200-7.

[25] Cockcroft DW and Gault MH: Prediction of creatinine clearance from serum creatinine. Nephron 1976, 16: 31-41.

[26] Chen BM, Xia LW, Zhao RQ. Determination of NG, NG-dimethylarginine in human plasma by high performance liquid chromatography. J Chromatogr B Biomed Sci Appl 1997;692:467-471.

[27] Bories PN, Bories C. Nitrate determination in biological fluids by an enzymatic one-step assay with nitrate reductase. Clin Chem 1995;41:904-907.

[28] Nakamura T, Sato E, Fujiwara N. Ezetimibe decreases serum levels of asymmetric dimethylarginine (ADMA) and ameliorates renal injury in non-diabetic cronic kidney disease patients in a cholesterol-independent manner. Pharm Res 2009;60(6):525-528.

[29] Leone A, Moncada S, Vallance P, Calver A and Collier J. Accumulation of an endogenous inhibitor of nitric oxide synthesis in chronic renal failure. 1992; 339(8793): 572-575.

[30] Raij L, Jaimes E, del Castillo D, Guerra J and Westberg G. Pathophysiology of the vascular wall: the role of nitric oxide in renal disease. Prostaglandins, Leukotrienes and Essential Fatty Acids 1996;54(1):53-58.

[31] Fliser D, Kronenberg F, Kielstein JT. Asymmetric dimethylarginine and progression of chronic kidney disease: The Mild to Moderate Kidney Disease Study. J Am Soc Nephrol 2005;16:1-6.

[32] Schmitt B, Wolters M, Kressel G, et al. Effects of combined supplementation with B vitamins and antioxidants on plasma levels of asymmetric dimethylarginine (ADMA) in subjects with elevated risk for cardiovascular disease.Atherosclerosis. 2007 Jul;193(1):168-76.

[33] Ninomiya T, Kiyohara Y, Kubo M. Hyperhomocysteinemia and the development of chronic kidney disease in a general population: The Hisayama study. Am J Kid Dis 2004;44(3):437-445. 


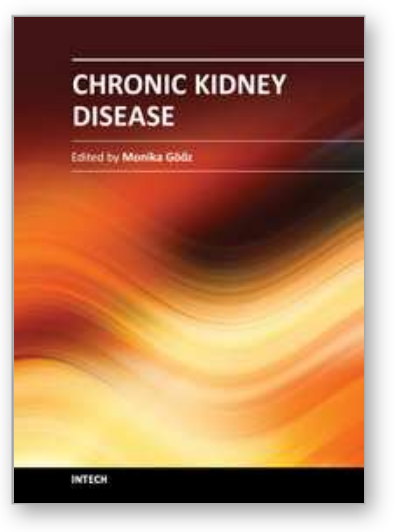

\author{
Chronic Kidney Disease \\ Edited by Prof. Monika Göőz
}

ISBN 978-953-51-0171-0

Hard cover, 444 pages

Publisher InTech

Published online 16, March, 2012

Published in print edition March, 2012

Chronic kidney disease is an increasing health and economical problem in our world. Obesity and diabetes mellitus, the two most common cause of CKD, are becoming epidemic in our societies. Education on healthy lifestyle and diet is becoming more and more important for reducing the number of type 2 diabetics and patients with hypertension. Education of our patients is also crucial for successful maintenance therapy. There are, however, certain other factors leading to CKD, for instance the genetic predisposition in the case of polycystic kidney disease or type 1 diabetes, where education alone is not enough.

\title{
How to reference
}

In order to correctly reference this scholarly work, feel free to copy and paste the following:

A. Atamer, S. Alisir Ecder, Y. Atamer, Y. Kocyigit, N. Bozkurt Yigit and T. Ecder (2012). The Effects of Asymmetric Dimethylarginine (ADMA), Nitric Oxide (NO) and Homocysteine (Hcy) on Progression of Mild Chronic Kidney Disease (CKD): Relationship Between Clinical and Biochemical Parameters, Chronic Kidney Disease, Prof. Monika Göőz (Ed.), ISBN: 978-953-51-0171-0, InTech, Available from:

http://www.intechopen.com/books/chronic-kidney-disease/the-effects-of-asymmetric-dimethylarginine-admanitric-oxide-no-and-homocysteine-hcy-on-progression-

\section{INTECH}

open science | open minds

\section{InTech Europe}

University Campus STeP Ri

Slavka Krautzeka 83/A

51000 Rijeka, Croatia

Phone: +385 (51) 770447

Fax: +385 (51) 686166

www.intechopen.com

\section{InTech China}

Unit 405, Office Block, Hotel Equatorial Shanghai

No.65, Yan An Road (West), Shanghai, 200040, China

中国上海市延安西路65号上海国际贵都大饭店办公楼 405 单元

Phone: +86-21-62489820

Fax: +86-21-62489821 
(C) 2012 The Author(s). Licensee IntechOpen. This is an open access article distributed under the terms of the Creative Commons Attribution 3.0 License, which permits unrestricted use, distribution, and reproduction in any medium, provided the original work is properly cited. 